\title{
The initial impacts of Minimum Energy Efficiency Standards (MEES) in England
}

Article

Accepted Version

Sayce, S. L. and Hossain, S. M. (2020) The initial impacts of Minimum Energy Efficiency Standards (MEES) in England. Journal of Property Investment \& Finance. ISSN 1463-578X doi: https://doi.org/10.1108/JPIF-01-2020-0013 Available at https://centaur.reading.ac.uk/89549/

It is advisable to refer to the publisher's version if you intend to cite from the work. See Guidance on citing.

To link to this article DOI: http://dx.doi.org/10.1108/JPIF-01-2020-0013

Publisher: Emerald Group Publishing Limited

All outputs in CentAUR are protected by Intellectual Property Rights law, including copyright law. Copyright and IPR is retained by the creators or other copyright holders. Terms and conditions for use of this material are defined in the End User Agreement.

\section{www.reading.ac.uk/centaur}

\section{CentAUR}

Central Archive at the University of Reading

Reading's research outputs online 


\title{
The Initial Impacts of Minimum Energy Efficiency Standards (MEES) in England
}

\begin{abstract}
Purpose - The paper investigates the initial impacts on asset management and valuation practice of the Minimum Energy Efficiency Standards (MEES) introduced in England and Wales from April 2018 for new lettings.

Design/Methodology/Approach - The paper reports findings from a small-scale pilot study of valuers, asset managers, lawyers and building consultants. Interviews were conducted over the Summer of 2019 and explored the impact on practice and market values and perceived links to the carbon reduction agenda. Data were analysed thematically manually and using NVivo software.
\end{abstract}

Findings - Participants welcomed MEES but many had doubts about the use of Energy Performance Certificates (EPCs) as the appropriate baseline measure. Compliance was perceived as too easy; further, enforcement is not occurring. Vanguard investors have aligned portfolios for carbon reduction; others have not. Lease practices are changing with landlords seeking greater control over tenant behaviours. Valuers reported that whilst MEES consideration is embedded in due diligence processes, there is limited value impact.

Research implications/limitations - The study is limited by its small-scale and that the MEES regulations are not yet fully implemented. However, the research provides early findings and lays out recommendations for future research by identifying areas in which the regulations are/are not proving effective to date.

Practical implications - The findings will inform investors, consultants and policy makers.

Social Implications - Achieving energy efficiency in buildings is critical to driving down carbon emission; it also has economic and social benefits through cost savings and reducing fuel poverty..

Originality/Value - Believed to be the first post-implementation qualitative study of MEES.

Keywords - Energy Performance Certificates; Minimum Energy Efficiency Standards; Market Impact; Valuers; Asset Management.

Paper type Research paper

\section{Introduction}

The Case for Minimum Energy Standards in Buildings

UK government has long held ambitions to move towards a zero-carbon economy. One important step was the Climate Change Act (2008) which set up a carbon target of $80 \%$ reduction by 2050, progress towards which has been made (BEIS, 2019[a]); however this target was enhanced in 2019 to zero-carbon by 2050 (BEIS, 2019[b]) in the light of increased concerns around climate change. 
Europe in general has an old and energy inefficient stock (BPIE, 2017); further there is a slow rate of building replacement (Balaras et al. 2007; Artola, 2016) and rented stock is likely to have a lower efficiency than owner-occupied stock (WGBC, 2018). Therefore, upgrades to the built stock are critical to achieving climate change targets (IPCC, 2018). Collectively these findings create a strong case for mandating energy efficiency improvements in investment stock.

However, the European response has generally been encouragement rather than imposition (BPIE, 2014), The prime vehicle is the Energy Performance Certificates (EPCs) introduced in 2008 requiring buildings to be certified prior to sale or letting with the intention of creating demand shift through transparency. In the UK, EPCs grade buildings from A (best) to G (worst). However, EPCs are not a true measure of energy demand because they are asset (or fabric) ratings; further, they do not require any action to be taken in respect of poorly graded buildings and, once obtained, a certificate has a life of 10 years. But, until the introduction of Minimum Energy Efficiency Standards (MEES) in 2018, they were the only mandated measure in England and Wales.

\section{Introducing the Minimum Energy Efficiency Standards (MEES) Regulations}

Minimum Energy Efficiency Standards (MEES) in England and Wales of investment stock were enacted in the Energy Act (2011); regulations were issued in 2015, following industry consultation, were subsequently clarified and came into force for new lettings from April 2018. Existing lettings come into scope in April 2020 (domestic) and April 2023 (non-domestic).

The extant minimum standard is an $\mathrm{E}$ (on an $\mathrm{A}-\mathrm{G}$ scale), though the intention, enshrined in the Clean Growth Strategy (BEIS, 2017), is to increase the minimum standards progressively; at the time this study was undertaken, no planned trajectory had been announced. Since then the government has consulted on future options with a stated preference for the standards required to be raised to a $\mathrm{B}$, which exceeds many new build specifications, by 2030 (BEIS, 2019 [d]). There is a recognition that setting the bar so high could result in value disruption and 'stranding' of assets (Muldoon-Smith and Greenhalgh, 2019).

To balance the risks to the market with incentives to comply, the regulations provide both permanent and temporary exemptions. The former primarily relates to heritage assets, though there is no exemption for listed buildings per se and to temporary buildings. The latter refers to a tenant's refusal to grant consent for the landlord to undertake work; to lack of cost effectiveness using a seven-year payback formula for non-domestic property and a cap of $£ 3,500$ cost for residential; or if the work would devalue the asset by $5 \%$ or more.

Enforcement measures, with significant penalties for each breach, aim to provide a strong disincentive for non-compliance with fines of up to a maximum of $£ 5,000$ for domestic property and $£ 150,000$ for non-domestic buildings to be enforced by local authorities.

In summary, the case for introducing minimum energy standards in rented stock in the UK is predicated on both national and international policies driving towards the goal of eliminating carbon from the built stock by 2050. It is acknowledged that it can only be a part of a suite of measures, given its restricted application scope. But currently MEES is the only mandated measure to positively drive buildings' energy efficiency. However, whether it will achieve its aims is not certain because it: 
- impacts only a minority of the built stock (PIA, 2017), and even then, with some exceptions;

- is not strictly a carbon measure because it is based on the EPC and, by implication, relies on the accuracy of the EPC;

- relies on investor compliance and effective enforcement; and

- depends on the levels of the planned trajectory.

\section{The Anticipated Impacts of MEES}

MEES had a long lead-in period to help market participants adjust although detailed guidance to landlords was not issued until 2017. During the lead-in, there was speculation about the likely impact, with Alker (2017) claiming MEES "could be the single most significant piece of legislation to affect our existing building stock in a generation, affecting a huge swathe of rented properties." Prior to this, Sweetts et al., (2014) had concluded that approximately 36\% of commercial EPC rated properties were likely to be affected by MEES with offices being the most affected asset class, but low value industrials being most difficult to be made compliant under the cost-effectiveness rules.

The impact on investment value and the need for proactive management were two identified considerations, and to assist owners and their advisers, the RICS (2018[a]) published guidance to asset managers and real estate valuers to better ensure good knowledge and optimal advice.

It was anticipated that investors would 'future-proof' their portfolios in anticipation of implementation in a 'rush to the top' (Montlake and Gelb (2018) and Better Buildings Partnership (2017) confirmed that at least one major investor had achieved full portfolio compliance. However, McAllister and Nase (2019), in a study of London offices covering the pre-implementation period, found little evidence of anticipatory retrofits except in larger buildings which they opined were probably more valuable buildings owned by larger investors. Similarly, a hedonic study of regional offices (Booker, 2019) could not establish any discernible pre-implementation MEES impact.

Since MEES commencement, limited evidence of possible impact has been published and none contain post-implementation evidence (for example Dowding et al., 2019; French, 2019; Hartley, 2019). This paper fills that gap by providing insights one year on after implementation.

\section{Aims}

The aim of the study, conducted over the summer of 2019, was to provide insight into the initial effectiveness of the MEES regulations by investigating:

- actions taken and planned by landlords either to work ahead of regulation and comply or to circumvent;

- the impact on market values viewed through the lens of practicing valuers; and

- the extent to which the regulations would meaningfully contribute to the decarbonisation of buildings agenda.

\section{Working Method}


Given only one year had elapsed since the introduction of phase one of the regulation, it was considered too early to assess the impact of MEES quantitatively; therefore, the decision was taken to undertake in-depth semi-structured interviews. The aim was this would be a pilot study to judge the 'direction of travel' in terms of experiences.

Some 25 people were interviewed either face to face or by telephone; most were senior practitioners, with national experience. The sample comprised valuers (13), lawyers (3), building or/and asset management consultants (6) and property investor representatives (3). Whilst the majority (18 respondents) were exclusively concerned with commercial stock, seven respondents, including one lawyer, one investor and five valuers were operating exclusively or partially within the residential field. Most, but not all, worked from a London base, but many had national practice remits. Two valuers worked only within a regional level. There was a deliberate exclusion of individual large-scale investors who operate within the vanguard of environment and social governance principles, although a representative body was interviewed. All interviewees had extensive experience of dealing with property owners and tenants, primarily through an advisory capacity, often advising specifically on MEES or valuing or managing assets for which there are MEES regulatory implications. It is recognised that all such small-scale qualitative studies have potential bias but this was reduced as as far as was practicable by careful choice of participants..

Interviews were recorded and written records of key findings were compiled for each interview and verified by the interviewees who had the opportunity to consider, reflect and confirm their views. The summary transcripts form the basis of the thematic analysis which has been conducted manually and using NVivo software.

The interview questions were adjusted for each interviewee and explored a range of issues relating to MEES including technical issues, such as enforcement and exemptions, but the primary focus was on their experience of market impact and owner responses to the regulation. Depending on their individual practice arena, questions explored the impact on values and valuation practices, asset management and portfolio preparedness and lease structures and clauses. All interviewees were then asked for their wider views, including the likelihood of MEES succeeding in supporting market transformation. Finally, they were asked whether, in their view, the market was recognising either or both the link between the regulation and the climate change agenda and the government's likely future trajectory.

\section{Findings}

The findings are presented under a series of themes that arose from analysis of the transcripts. Brief quotations have been included but are not attributed to preserve anonymity.

\section{MEES: effective in raising awareness but not necessarily action}

The headline finding is that MEES is a "step in the right direction", welcomed almost unanimously by interviewees opining that it had raised awareness of the need to promote energy efficiency in buildings. Whilst confirming that some of the leading players " $h a d$ responded before it was in force" many smaller landlords and some lenders lacked full awareness, even where they were dealing with residential property for which existing tenancies are caught in April 2020.

Among interviewees, there was disparity of knowledge with some specialist consultants and asset managers displaying expert technical knowledge. Valuers tended to be less knowledgeable possibly as their clients had "not taken this date on board yet." and they 
confirmed that their role is to reflect markets and were not seeing MEES widely reflected in market behaviours. What can tentatively be drawn from this is that, whilst MEES has raised awareness, little action has ensured except among vanguard investors. In most cases actions are still determined by the "here and now" with "little evidence of clients being stimulated by MEES to upgrade their buildings."

Instead, the overall view was that compliance was too easy and simply often a case of changing the lightbulbs at low expense and other "cheap compliance tricks". Counter to this was the view that even "a switch of lighting to LED is a move in the right direction." This ease of compliance was the reason quoted for the small take up of temporary exemptions to date in the non-domestic sector, backing up the data compiled by BEIS ${ }^{1}$, which revealed that, in the 12 months since MEES was introduced only 130 exemptions in relation to non-domestic buildings had been registered.

Another reason for lack of action identified by several interviewees was a lack of enforcement which was considered could lead to large-scale non-compliance as the "lack of any sign of enforcement has meant that people are now taking MEES less seriously than they were prior to April 2018." This was viewed as particularly problematic given that non-compliant properties were more likely to be held in lower value portfolios owned by investors lacking specialist advice.

\section{Matters concerning the EPC}

MEES regulations are intrinsically linked to EPCs; this presumes that the EPC is an appropriate measure of energy efficiency in buildings and, by implication raising EPC levels will support transformation towards a low (or zero) carbon economy. However, many interviewees, notably the asset managers and building consultants, had concerns about the reliance on EPCs on grounds of accuracy and appropriateness.

\section{Accuracy}

The accuracy of the EPC is fundamental to delivering the ambitions of MEES; if it is not a trusted measure, MEES will be viewed neither as a positive move towards delivering government targets nor will upgrades for compliance yield fabric efficiency.

Previous research (European Commission, 2013; RICS, 2019) has recognised that EPCs, particularly pre 2012, are often inaccurate with the results being dependent in no small measure on the thoroughness of the EPC survey, the skill of the assessor and the fee paid. Whilst acknowledging that changes in 2012 to the methodology underpinning EPCs had resulted in greater accuracy, several respondents said commissioning a re-assessment made many noncompliant buildings compliant without any work being undertaken. But concerns remained about a lack of trust and that some assessors might "succumb to client pressure" to provide a report of a compliant level grade; as one put it "even though it is no longer the 'wild west' that it was, there is still the view out there that you can shop around for a better EPC." To valuers, the EPC report is often unhelpful in determining the potential impacts on market value as "they don't say how and on what basis the assessor came to their conclusions" and are "not sufficiently transparent and accurate." This is a matter recognised by government who state that it is often "difficult to understand how accurate a rating of energy performance EPCs are" (BEIS/MHCLG, 2018 p:25).

\footnotetext{
${ }^{1}$ Figures on exemptions supplied by BEIS in correspondence with the author.
} 


\section{Appropriateness of EPC as a basis for MEES}

Several interviewees expressed fundamental concerns about the appropriateness of EPC as a tool to reducing carbon as the EPC is an asset rating - not a performance measure; it is theoretical, not practical. Interviewees pointed to the Australian system, NABERS, which measures performance, suggesting that this might provide a more useful measure as it has led to "made a difference" in Australia. Whilst there are plans to develop a UK version of NABERS on a voluntary basis for commercial property, this would only apply initially to office properties sitting within the portfolios of engaged institutional investors.

Further, several interviewees considered that linking any regulation to a measure that lasts for ten years makes little sense and therefore advocated a link to Display Energy Certificates (DEC). MEES, it was argued, cannot necessarily deliver a carbon reduction because it doesn't tell the occupier how efficiently the building is operating.

\section{Market Impacts}

Investor strategies

The pilot study confirmed the views that many large-scale investors have taken steps to align their portfolios beyond regulatory requirements well in advance of the formal introduction; for others the aim is compliance and no more. It was reported that many large investors had been adjusting their strategies ever since MEES was first placed on the statute book in 2011; they had audited their portfolios and where the stock was strategically important had improved "beyond compliance" but generally they disposed of low performers and bought "those assets with no issues," defined as those with at least a D or possibly a $\mathrm{C}$ certificate. There was little or no recognition that assets rated $\mathrm{D}$ would in time become non-compliant through regulatory change. However, for smaller investors with smaller or secondary portfolios "just complying is more likely to be the aim".

In summary, instead of triggering significant retrofit works, disposal and acquisition strategies are seeing the lower grade stock being sold to other investors with lower sustainability aspirations or those with active 'value-add' policies.

\section{Valuation Practice}

Under the then RICS professional requirements (RICS, 2017: VPS 2) valuers are "strongly advised to collect and record appropriate and sufficient sustainability data, ... even if it does not currently impact on value." Specific guidance was issued to valuers and asset managers in the UK in 2018 (RICS, 2018[a]) in advance of MEES' implementation. Previous studies of valuation practice have revealed little evidence that energy and sustainability matters were routinely integrated into practice (Michl et al. 2016; Sayce, 2018; Warren-Myers, 2018; Le and Warren-Myers, 2019). Therefore, valuers were asked to comment on whether MEES had impacted their processes and practice.

Interviewees reported that "MEES/EPC is now fully embedded in the valuation process". However, deeper questioning revealed that some valuers take the EPC at face value without questioning whether it is old or likely to be inaccurate for any other reason. This is an area in which due diligence appears still to require deepening, but it is recognised that the time allowed to conduct the valuation and the fee level may lead to very heavy reliance on information supplied by the commissioning client. 
It is one thing to collect data; it is another for it to influence judgment as to market value, so valuers were asked whether and how they reflected MEES in their valuations. Globally, there has been much research seeking to link real estate values with sustainability ratings, but the number of UK studies has been limited. Fuerst et al. $(2015 ; 2016)$ concluded that there was emerging evidence of price differentiation based on EPC; but whether this is by a 'green' premium partially caused by a shortage of high grade stock (Fuerst et al., 2017) or to an emergence of a 'brown discount' for less good stock (RICS, 2019) is questionable. From the interviews the dominant view of valuers was that "generally 'green' issues do not really arise".

However, moving forward they considered that "brown discounting is likely to emerge" leading to some assets becoming 'stranded assets', notably in low value areas, as anticipated by Muldoon-smith and Greenhalgh (2019) and Booker (2019). Already some are being marked down in value, as was anticipated by French and Antill, (2018). This is being done either through an adjustment to the capitalisation yield, based on the perception of risk to the future lettability, or to reflect a potential capital expenditure to ensure compliance, in line with RICS guidance on MEES (RICS, 2018 [a]).

One emerging relationship between MEES and value raised was the attitude of lenders. It emerged that practice is very variable. While some banks do not include EPC data on their loan portfolios, most at least "have it on their radar" and require a letter grade. Within the residential sector, one valuer reported that MEES compliance was now a reporting requirement of some lenders leading to non-compliant stockbeing "labelled as not suitable for secured loan and therefore nil rated". Other lenders, however, ask for a valuation on the assumption (if not a fact) that the property will continue to be lettable and compliant; any risk to value is reported but not quantified. It is apparent that lenders' attitudes may be critical to the impact of MEES moving forward.

\section{Leasing practice}

It had been expected that MEES would impact on the landlord and tenant relationship and the drafting and management of commercial leases (Turley and Sayce (2015); Mulliner and Kirsten (2017); Hartley, 2019). Questions to asset managers and lawyers sought to discover what, if any, changes had taken place and, in particular, whether interests in 'green leases' (see for example, Hinnells et al, 2008; Bright and Dixie, 2014; Patrick and Bright, 2016) had grown as a result of MEES.

The overriding responses was that the landlord's "key objective is to mitigate risk" by ensuring that "the landlord has control of the process around EPCs" and several interviewees pointed to changes to the Model Lease Clauses ${ }^{2}$ which had changed in anticipation of MEES and stronger controls to landlords over works undertaken by tenants by:

- preventing tenants from applying for a new EPC without the landlord's consent;

- making greater use of licences prior to lease to control fit-out work, especially for retail premises;

- reducing the number of 'shell and core' arrangements in offices;

- inserting clauses to enable them to gain access to undertake works in relation to MEES, thus obviating issues around gaining tenant consent;

\footnotetext{
2 The Model Lease Clauses website and model leases were originally commissioned by the British Property Federation and the terms are kept up to date by a working group which aims to act impartially between landlords and tenants. The MEES alterations can be found at https://modelcommerciallease.co.uk/july-2016changes/
} 
It was acknowledged that, whilst landlords were seeking value protection, uncertainties around interpretation of service charge clauses and obligations on tenants to ensure statutory compliance were regarded as whole areas "in which litigation will ensue in the future," although respondents considered that most landlords would not seek to pass on liabilities that were intended by the regulations to fall to the landlord.

However, respondents pointed to ambiguities in the now mandated the RICS Commercial Service Charge Standard (RICS, 2018[b]) which states that, although the costs of obtaining an EPC is not a legitimate service charge cost, "any subsequent costs of improving energy efficiency might comprise a legitimate service charge item, as long as there is a proportionate cost benefit to tenants." (RICS, 2018[b] p:44). Some said it could be argued to allow landlords to recover compliance costs.

These potential conflict issues were balanced by a positive finding that several asset managers and lawyers had observed a resurgence of interest in 'green leases' with tenants said to be "getting used to them" which confirms the findings of Patrick and Bright (2016) who concluded that, at least for institutional and large property companies, some green lease clauses are beginning to be embedded as part of company sustainability strategies.

In summary, changes in lease wording had been taking place prior to 2018; however, it is only as the regulations have come into force that issues such as dealing with fit-out and control of the EPC level have really come into play; it will take time to ascertain what arguments will result in relation to service charges and lease determination and how they may be determined.

\section{Wider implications: a trajectory to a zero-carbon economy?}

The final part of the interview was intended to be open-ended and speculative. At the time of the interviews, the Committee on Climate Change had recently published its 2019 progress report advising UK government to increase its carbon targets from an $80 \%$ reduction by 2050 to zero carbon by 2050 (Committee on Climate Change, 2019 [a]); this it estimated would require a decarbonisation investment in buildings of some £15-20 billion (Committee on Climate Change, 2019 p:28). These recommendations passed into law in June 2019 (BEIS, 2019 [c]) at the start of the study period. The interviews also coincided with a period of civil unrest by the Extinction Rebellion movement and the high profiling of climate activists, including Thunberg. The questions sought to establish whether interviewees considered market players were connecting such actions to policies such as MEES: was MEES seen to be integral to the wider policy debate around climate change?

The potential of current MEES regulations to effect meaningful change.

Whilst MEES was considered a welcome measure, respondents were less convinced that they would lead to market 'transformation.' Reasons for this can be summarised as:

- MEES is simply the wrong tool to reduce carbon, even if properly enforced;

- it will take too long for the targets to be met;

- it only addresses the investment sector and not the social rented or owner-occupied buildings; and

- it is simply not radical enough.

In terms of the last point, there was concern that it would be difficult to "gain market shift without damaging the market and many people going bust," a result seen as undesirable and 
unacceptable and one that had not occurred with the current regulations. There was therefore an implicit acceptance that MEES would help as a "step in the right direction" but no more.

A wider awareness of connecting buildings to the Climate Change agenda

Whilst the above represented the views of respondents on MEES, they were also asked, in the light of policy changes outlined above and the social and climate context, whether in their opinion, participants within the property markets had begun to make the connection between the regulatory framework and the strengthening climate change agenda.

Not all interviewees ventured a view, but of those who did, none saw the market factoring in the likelihood that MEES was only the start of a regulatory road in which the need for very significant investment would be required. The dominant view was that the people have "simply not made the connection yet between (aspiration of zero carbon) and the property market." Further there was an argued lack of awareness among some advisers so that "The journey will be difficult. . no one is talking about a zero-carbon scenario-people are not even aware yet of the phasing out of gas in new build from 2025."

This did not mean that interviewees were disconnected personally with the climate change agenda, but several ventured the opinion that, in the words of one interviewee, "the younger generation coming through have much stronger awareness - over time there will be an alignment to a common purpose and a tipping point will be reached." But for this group, for now, MEES was viewed essentially as a matter of immediacy - a requirement to comply.

\section{Discussion and Conclusions}

\section{Discussion}

The research was conducted over the summer of 2019, just over a year after of MEES had been implemented for new lettings; to date existing lettings are still not directly affected. The regulations had been widely anticipated, and government and professional body advice had been issued and widely disseminated. Therefore, it could have been expected therefore that interviewees, who primarily were senior consultants, would have a good working knowledge of both MEES and its impacts on their property sector. Although some interviewees were primarily practicing in the residential sector, most were concerned with commercial buildings where the potential penalties for non-compliance are higher and lease commitments longer, thereby with biggest potential implications.

The interviews coincided with a period of significant media attention on climate change and during the period government's carbon target changed from $80 \%$ reduction to zero-carbon by 2050. Therefore, it was anticipated that at least some of those interviewed would be advising their clients in relation to possible more stringent MEES targets, even though the quantum of these was unknown.

However, it became apparent that, among valuers, baseline knowledge of MEES exemptions and penalties was variable and sometimes limited; further, except for building consultants/asset managers, there was limited knowledge as to the timing and details of the full introduction of MEES in 2020 (residential) and 2023 (commercial). Yet such matters are critical to valuation and asset management advice. Further, the findings pointed to respondents reporting virtually no connectivity between the climate "crisis" and policy responses with the operation of the 
property market. The future trajectory was simply not on the advice 'radar' for all but a very few.

Despite this, MEES is perceived as influencing behaviours, raising awareness and pushing energy efficiency up the investment agenda. Logically, the consequence should be either investment in assets both to ensure current compliance and prepare for further tightening of the regulations, or divestment. The interviews revealed a range of responses with the ease of compliance to current required standards being cited by several people as the normal response. If indeed, in most cases compliance can be achieved by commissioning a better EPC, the regulations will have no significant impact. Even if they lead to changing lighting systems to ensure compliance, carbon savings will be very limited. Little evidence was found that deep retrofits were taking place, with interviewees suggesting that investors would either undertake work at the most appropriate time - notably when a void occurred, or dispose. Undertaking works in-cycle is is good asset management practice; disposal is simply shunting the issue on to someone else, possibly and investor with less financial ability to address the refurbishment issue.

Such assets, it is argued, are likely to suffer brown discounting, and this view was shared by several of the valuers who had observed some 'price chipping'. This was viewed as more likely than the emergence of a 'green' premium for highly rated stock, although the impact on value is not yet fully felt. The exception is for residential secured lending where the binary approach taken by some lenders appears to impact values most. The variable knowledge shown by valuers was perhaps surprising given the potential MEES implications; even more was the unquestioning by some regarding the veracity of the EPC, or assumptions as to compliance where this was not the fact.

The clearest impact found was on lease practices; by way of preventing tenants making alterations which could lower the EPC rating and an increase in agreements for lease to better control fitouts. There was also a renewed interest in green leases. Whilst these changes are beneficial and signal increases in the engagement of investors with their stock, there were other, less positive 'takeaways' with some evidence of landlords attempting to shift the costs of compliance to the tenant through service charges, although the legality of so doing was viewed as uncertain.

Overall the findings suggest the regulations are viewed as a hurdle to overcome to protect immediate investment value, rather than a measure intended to secure long-term enhancement; but it was also seen by most as too low a hurdle and lacking effective enforcement.

\section{Conclusions}

This was a pilot study focused primarily, not exclusively, on commercial properties. Whilst interviewee choice provided a range of expertise and experience, the study is not comprehensive, so conclusions must be tentative. They do, however, provide early insight into both the positive and negative market impacts of MEES on value, asset management and lease practices.

A positive conclusion is that MEES has raised awareness of energy efficiency matters among those not previously engaged with corporate responsibility and climate change mitigation. Energy matters are now part of the 'day to day' agenda of asset managers and lease drafters, although, to date, the impact on investment values has been only modest 'price chipping.' 
On the negative side, it has not so far led to significant building improvements, a key objective of the regulations, although this may be due in part to prior actions by vanguard investors and the need to tie in works with major refurbishment cycle, especially as temporary exemptions are possible. But, as suggested above, some major investors may have sold stock which was likely to be non-compliant either initially or in the longer term. This potentially may lead to the poorer stock becoming concentrated in the portfolios of those with less ability to lever funds for improvements, leading to loss of value and exemption from compliance due to lack of costeffectiveness. In turn this may lead, not to improvement works, but to stranded assets or loss of stock, with inevitable social - and carbon - consequences.

Further, to those with lower value portfolios, residential or commercial, the approach is towards doing the minimum - such as lighting upgrades - to ensure compliance. Compliance is seen as easy and cheap to achieve; sometimes only the cost of obtaining a more rigorous EPC certificate. If this is so, it will not drive down carbon emissions.

It was in leasing policies that MEES could be argued to be creating a subtle, positive, change. Although some landlords might seek to pass compliance costs to tenants, this was thought to be a minority. What was more evident was that landlords now seek more management control over their assets to protect or enhance energy performance leading to engagement and dialogue between the parties. If this is so, it presents real opportunities for timely and appropriate investment in buildings.

In conclusion, MEES is the start of a journey. Currently it is seen as a matter of compliance; even the next steps of application to existing leases have not been fully recognised or embraced by most investors, judging by the views expressed. And there is a real lack of preparedness and awareness of the likely trajectory. Further, it is not capable, even when strengthened, of being the right mechanism for ensuring upgrading of stock sufficient to meet government objectives; it is but one small building block.

On limited evidence, the results suggest areas for potential further and deeper investigation. First, the linking of EPCs with MEES has produced some scepticism. As the requirements of MEES are tightened, the basis on which those standards are based is would benefit from deeper consideration on whether EPCs remain the measure of choice. Second, the combination of easy compliance, lack of enforcement and (at least within the commercial sector) low usage of exemptions suggests that the suggested policy of strengthening the requirements is critical. However, a better understanding of how retrofits work can be incentivised or supported without too high a social, environmental and economic cost in terms of stranded assets would help.

Finally, if the findings of this small study could be regarded as being representative of the industry, there is a marked disconnect between personal acknowledgement of the need to respond to climate change, and the prevailing response to MEES as a short-term regulatory hurdle. This does not provide comfort in the current actions of property market participants, other than the 'vanguard' investors, to deliver 'beyond compliance' of the regulatory framework; there is an incompatibility of ambition. While MEES may be influential moving forward, property decisions are critical to delivering on the carbon challenge so perhaps the words of Thunberg (2020) should be borne in mind "the transition isn't going to be easy. It will be hard. And unless we start facing this now together, with all cards on the table, we won't be able to solve this in time." 


\section{References}

Alker, J (2017) Quoted by the National Energy Foundation at http://www.nef.org.uk/aboutus/insights/2015-energy-efficiency-regulations-a-real-game-changer-for-the-property-sec

Artola, I., Rademaekers, K., Williams, R. and Yearwood, J., 2016. Boosting Building Renovation: What Potential and Value for Europe?: Study. European Parliament. Available at:

www.europarl.europa.eu/RegData/etudes/STUD/2016/587326/IPOL_STU(2016)587326_EN. pdf

Balaras, C.A., Gaglia, A.G., Georgopoulou, E., Mirasgedis, S., Sarafidis, Y. and Lalas, D.P., 2007 European residential buildings and empirical assessment of the Hellenic building stock, energy consumption, emissions and potential energy savings, article in Building and Environment, Vol 42 No 3 pp. 1298-1314, Elsevier, 2007.

BEIS (Department of Business and Industrial Strategy) 2017 The Clean Growth Strategy Leading the way to a low carbon future available from https://www.gov.uk/government/publications/clean-growth-strategy

BEIS (Business, Energy and Industrial Strategy Committee) 2019 [a] Energy efficiency: building towards net zero https://publications.parliament.uk/pa/cm201719/cmselect/cmbeis/1730/1730.pdf

BEIS (Department of Business and Industrial Strategy Committee 2019 [b] New target will require the $U K$ to bring all greenhouse gas emissions to net zero by 2050.https://www.gov.uk/government/news/uk-becomes-first-major-economy-to-pass-netzero-emissions-law

BEIS (Department of Business and Industrial Strategy Committee 2019 [c] UK becomes first major economy to pass net zero emissions law available from https://www.gov.uk/government/news/uk-becomes-first-major-economy-to-pass-net-zeroemissions-lawBEIS (Department for Business, Energy and Industrial strategy) 2019 [d] The Non-domestic Private Rented Sector Minimum energy Efficiency Standards: the future trajectory to 2030 available from

https://assets.publishing.service.gov.uk/government/uploads/system/uploads/attachment_data /file/839362/future-trajectory-non-dom-prs-regulations-consultation.pdf

BEIS (Department for Business, Energy and Industrial strategy) and MHCLG (Ministry of Housing, Communities and Local Government) 2018 Call for Evidence: Energy Performance Certificates for Buildings available from

https://assets.publishing.service.gov.uk/government/uploads/system/uploads/attachment data/ file/729853/epcs-call-for-evidence.pdf

Better Buildings Partnership (2017) CLS Holdings De-risks Entire UK Portfolio for MEES reported at http://www.betterbuildingspartnership.co.uk/cls-holdings-de-risks-entire-ukportfolio-mees 
Booker, Y., 2019. Assessing the impact of the intensifying UK minimum energy efficiency standards (MEES) on regional office rental values. International Journal of Urban Sciences, pp.1-21.

BPIE (Building Performance Institute Europe) 2014 Renovation Strategies Of Selected Eu Countries Available from http://bpie.eu/wp-content/uploads/2015/10/Renovation-StrategiesEU-BPIE-2014.pdf

BPIE (Buildings Performance Institute Europe),2017 Factsheet - 97\% of buildings in the EU need to be upgraded, State of the building stock briefing, 2017. Available at: http://bpie.eu/wp-content/uploads/2017/12/State-of-the-building-stock-briefing Dic6.pdf

Bright, S. and Dixie, H., 2014. Evidence of green leases in England and Wales. International Journal of Law in the Built Environment, Vol 6 No 1/2(1/2) pp.6-20.

Committee on Climate Change, 2019 Net Zero - The UK's contribution to stopping global warming available at https://www.theccc.org.uk/publication/net-zero-the-uks-contribution-tostopping-global-warming/

Dowding, N., Lemmon, S. and White, P., 2019. The Minimum Energy Efficiency Standards: Energy Performance Certificates, carrying out energy efficiency improvements and the impact on dilapidations. Journal of Building Survey, Appraisal \& Valuation, Vol 8 No 2, pp.102-111.

European commission (DG Energy) 2013 Energy performance certificates in buildings and their impact on transaction prices and rents in selected $E U$ countries: final report available at https://ec.europa.eu/energy/sites/ener/files/documents/20130619energy_performance_certificates_in_buildings.pdf

French, N., 2019. The impact of Minimum Energy Efficiency Standards on the UK investment market: one year on. Journal of Property Investment \& Finance Vol 37 No 4, pp. 416- 423

French, N. and Antill, J. 2018, Property valuation in the UK: energy efficiency legislation and its impact on valuation", Journal of Property Investment \& Finance, Vol 36 No 4, pp. 383390.

Fuerst, F., McAllister, P., Nanda, A. and Wyatt, P. 2015. Does energy efficiency matter to home-buyers? An investigation of EPC ratings and transaction prices in England. Energy Economics Vol 48, pp.145-156

Fuerst, F., McAllister, P., Nanda, A. and Wyatt, P. 2016. Energy performance ratings and house prices in Wales: an empirical study. Energy Policy, Vol 92, pp.20-33.

Fuerst, F., Gabrieli, T. and McAllister, P., 2017. A green winner's curse? Investor behavior in the market for eco-certified office buildings. Economic Modelling, Vol 61, pp.137-146.

Hartley, S., 2019. The impact of Minimum Energy Efficiency Standards on dilapidations claims. Journal of Building Survey, Appraisal \& Valuation, Vol 8 No 2, pp.125-144.

Hinnells, M.; Bright, S.; langley, a.; Woodford, 1.; Schiellerup, P.; Bosteels, T. 2008. the greening of commercial leases, Journal of Property Investment and Finance Vol 26 No6, pp.941-991 
IPCC (Intergovernmental Panel on Climate Change) 2018, The IPCC and the sixth assessment cycle, 2018. Available at: www.ipcc.ch/site/assets/uploads/2018/09/AC6_brochure en.pdf

Le, T.T. and Warren-Myers, G., 2019 . An examination of sustainability reporting in valuation practice. Property Management Vol. 37 No. 1, pp. 136-153.

McAllister, P. and Nase, I., 2019. The impact of Minimum Energy Efficiency Standards: Some evidence from the London office market. Energy Policy, Vol 132, pp.714-722.

Michl, P., Lorenz, D., Lützkendorf, T. and Sayce, S., 2016. Reflecting sustainability in property valuation-a progress report. Journal of Property Investment \& Finance, Vol 34 No 6, pp.552577.

Montlake, D. and Gelb, S., 2018. Minimum Energy Efficiency Standards and steps to improve energy inefficient properties. Journal of Building Survey, Appraisal \& Valuation, Vol 7 No 2, pp.126-131.

Muldoon-Smith, K. and Greenhalgh, P., 2019. Suspect foundations: Developing an understanding of climate-related stranded assets in the global real estate sector. Energy Research \& Social Science, Vol 54, pp.60-67.

Mulliner, E. and Kirsten, L., 2017. Preparation for the Energy Act 2011 and minimum energy efficiency standards in UK commercial property. International Journal of Strategic Property Management, Vol 21 No 2, pp.183-198.

Patrick, J. and Bright, S., 2016. WICKED insights into the role of green leases. Conveyancer and Property Lawyer, June $5^{\text {th }} 2016$ No 4.

RICS, 2017 RICS Valuation- Global Standards 2017 available from https://www.rics.org/uk/upholding-professional-standards/sector-standards/valuation/redbook/red-book-2017/

RICS 2019 Energy efficiency and residential values: a changing European landscape: an RICS Insight Paper Available from https://www.rics.org/globalassets/ricswebsite/media/knowledge/research/insights/energy-efficiency-and-residential-values.pdf

RICS 2018 [a] Minimum Energy Efficiency Standards (MEES): Impact on UK property management and valuation: an RICS Insight Paper. Available from http://www.rics.org/Global/MEES impact UK property insight March 2018mr.pdf

RICS 2018[b] Service Charges in Commercial Property an RICS Professional Statement (1st Edition) Available from https://www.rics.org/globalassets/rics-website/media/upholdingprofessional-standards/sector-standards/real-estate/service-charges-in-commercial-property1st-edition.pdf

Sayce, S., 2018. Building sustainability into valuation and worth. Routledge Handbook of Sustainable Real Estate, pp.132-146.

Sweetts, SIAM and Kingston University 2014 Mapping the Impacts of Minimum Energy Efficiency Standards for Commercial Real Estate Final Report to the Green Construction Board. valuation and Demand Working Group: Project GCB630." 
The Property Industry Alliance (PIA) 2017 Property Data Report available from https://www.bpf.org.uk/sites/default/files/resources/PIA-Property-Data-Report-2017.PDF

Thunberg, G. 2020 'Our house is still on fire.' Speech on $21^{\text {st }}$ January to the Davos Economic Forum. Transcript available from https://www.express.co.uk/news/science/1231850/GretaThunberg-speech-in-full-Davos-forum-read-climate-change-activist-speech-transcript

Turley, M. and Sayce, S., 2015. Energy performance certificates in the context of sustainability and the impact on valuations. Journal of Property Investment \& Finance, Vol 33 No 5, pp.446455.

Warren-Myers, G., 2018. Valuing sustainability in commercial property in Australia. In Routledge Handbook of Sustainable Real Estate (pp. 95-113). Routledge.

World Green Building Council, 2018 Creating an Energy Efficient Mortgage for Europe: towards a new market standard available from http://www.worldgbc.org/green-mortgages 
Response to Referees comments

Recommendation: Minor Revision

Comments:

This is an interesting and topical paper which continues a 'conversation' on the introduction of MEES in England. The paper reports on a survey of 25 market participants mostly based in London. These comprise senior practitioners including valuers, lawyers, building consultants and property investor representatives. Thank you

The paper is well written and structured and makes some useful observations. Thank you

However, in its present form the paper is likely to be criticised for its relatively small sample size and its London centric database. This was work was a pilot study - as such it was deliberately - and inevitably - small-scale. We have made this clearer by adding pilot to the text and stressing it in the working methods section. In terms of being London Centric - several respondents had a national brief and were talking in relation to their national positioning. We hope this helps

Some of this criticism could be abated, if the Working Methods section could be expanded to provide a more detailed breakdown of the background and job role of the various participants. Moreover, information on how they were they chosen, how representative they are of the market would be helpful. We are told that only ' 7 are operating exclusively or partially within the residential field' - doubtful if this a sufficient evidence base to make judgements on the residential market. Thank you for these comments. We have made the information on respondents more fulsome and hope this deals with your concerns.

The "at least" solution is for the author(s) to accept more fully the indicative nature of survey and teh limitations thereof. We have so done - please see revised last paragraph pointing out the limitations. But we hope it shows a direction of travel and highlights the challenges to the successful full implementation and trajectory for MEES.

In summary, as a conversation piece the paper certainly has merit, but as an evidence base it is rather limited. Thank you for these comments which we fully accept - and I hope we have made the fact that the evidence base is limited has been made clear - 
The paper requires to be proof read. A further proof reading has taken place by 2 people!

Additional Questions:

1. Originality: Does the paper contain new and significant information adequate to justify publication?: Yes, some useful findings. Thank you

2. Relationship to Literature: Does the paper demonstrate an adequate understanding of the relevant literature in the field and cite an appropriate range of literature sources? Is any significant work ignored?: Yes, good coverage. Thank you

3. Methodology: Is the paper's argument built on an appropriate base of theory, concepts, or other ideas? Has the research or equivalent intellectual work on which the paper is based been well designed? Are the methods employed appropriate?: Yes in part, but evidence base could be significantly expanded. This point was picked up by both reviewers and we have taken it on board more explicitly in the abstract, working methods and the conclusions. As we have argued it was considered premature to do a large-scale study and by judicial choice of interviewees, combined with knowledge from literature as to the actions of some of the large-scale investors, we have endeavoured to produce a balanced view.

Need to provide more information on background of interviewees. We have done this now

4. Results: Are results presented clearly and analysed appropriately? Do the conclusions adequately tie together the other elements of the paper?: Yes, good thematic discussion. Thank you

5. Implications for research, practice and/or society: Does the paper identify clearly any implications for research, practice and/or society? Does the paper bridge the gap between theory and practice? How can the research be used in practice (economic and commercial impact), in teaching, to influence public policy, in research (contributing to the body of knowledge)? What is the impact upon society (influencing public attitudes, affecting quality of life)? Are these implications consistent with the findings and conclusions of the paper?: Yes, this is highly topical paper and continues an important conversation. Thank you

6. Quality of Communication: Does the paper clearly express its case, measured against the technical language of the field and the expected knowledge of the journal's readership? Has attention been paid to the clarity of expression and readability, such as sentence structure, jargon use, acronyms, etc.: Well written paper. Thank you 
Referee: 2

Recommendation: Minor Revision

Comments:

The initial impacts of minimum energy efficient standards in England

The paper was a pleasure to read, being well structured with an informative literature review and well referenced with a logical methodology, valid sample and interesting findings. Thank you

The author may care to review page 8 ("was MEES seen"), done page 9 ("trailed"),word changed page 10 ("what??")sentence changed! and the grammar in the penultimate paragraph on page 11. We have re-written this sentence to sort out the grammar and to take on board the concerns to ensure that the limitations of the study are fully taken on board.

Also, a final check that in text citations appear in the references and vice versa may be wise This has been done - we hope any glitches have now been dealt with!

Additional Questions:

1. Originality: Does the paper contain new and significant information adequate to justify publication?: Yes Thank you

2. Relationship to Literature: Does the paper demonstrate an adequate understanding of the relevant literature in the field and cite an appropriate range of literature sources? Is any significant work ignored?: Good literature review Thank you

3. Methodology: Is the paper's argument built on an appropriate base of theory, concepts, or other ideas? Has the research or equivalent intellectual work on which the paper is based been well designed? Are the methods employed appropriate?: Solid methodology and sample Thank you- but please see our response to Referee 1.

4. Results: Are results presented clearly and analysed appropriately? Do the conclusions adequately tie together the other elements of the paper?: Yes Thank you

5. Implications for research, practice and/or society: Does the paper identify clearly any implications for research, practice and/or society? Does the paper bridge the gap between theory and practice? How can the research be used in practice 
(economic and commercial impact), in teaching, to influence public policy, in research (contributing to the body of knowledge)? What is the impact upon society (influencing public attitudes, affecting quality of life)? Are these implications consistent with the findings and conclusions of the paper?: Well presented Thank you

6. Quality of Communication: Does the paper clearly express its case, measured against the technical language of the field and the expected knowledge of the journal's readership? Has attention been paid to the clarity of expression and readability, such as sentence structure, jargon use, acronyms, etc.: Clear Thank you 